\title{
Better Glycaemic Outcome, Low Levels of Acute Severe Complications, and High Patient Satisfaction in Routine Practice in Type 1 Diabetes Treated with an Insulin Puimp
}

\author{
H. J. Gjessing*, U. L. Jørgensen, C. C. Møller, J. Pedersen, E. Grodum, K. Schousboe \\ Diabetes Outpatient Clinic, Medical Department, Fredericia Hospital, Sygehus Lillebælt Dronningensgade 97 \\ 7000 Fredericia, Denmark \\ Email: " hans.gjessing@rsyd.dk
}

Received 12 August 2014; accepted 10 September 2014; accepted 5 October 2014

Copyright (C) 2014 by authors and Scientific Research Publishing Inc.

This work is licensed under the Creative Commons Attribution International License (CC BY). http://creativecommons.org/licenses/by/4.0/

\section{(c) (i) Open Access}

\section{Abstract}

Treatment of patients with Type 1 diabetes with continuous subcutaneous insulin infusion (CSII) was re-introduced in Denmark in this millennium and initiated in the diabetes clinic, Fredericia Hospital, in 2005. The aim of the present study was to present yearly data of quality from 2005 to 2013 from a clinical database of patients treated with CSII in routine practice. Methods: A database was established in 2009-2010. Data from 2005 to 2009 are retrospective, data from 2009 to 2013 prospective. From 2009, patient satisfaction was measured by validated questionnaires. Results: By 31 December 2013, the database contained data from 143 active patients. HbA1C (median and range) decreased from $64(40-126) \mathrm{mmol} / \mathrm{mol}(8.0(5.8-13.7) \%)(\mathrm{n}=104)$ to $60(36$ 98) $\mathrm{mmol} / \mathrm{mol}(7.6(5.4-11.1) \%)(n=134)(p<0.001)$ before and latest year on CSII. The improved glycaemic control was maintained each year until $\geq 5$ years after initiation of CSII $(p<0.01)$. There was no change in weight. The number of attacks of severe hypoglycaemia was reduced from 60 attacks in 21 patients $(n=104)$ the year before CSII to only 5 attacks in 5 patients in $2013(n=$ 134) ( $<0.01$ ), corresponding to an incidence of 3.7 episodes per 100 patient years. Each year after initiation of CSII until $\geq 5$ years, the number of episodes of severe hypoglycaemia was reduced (p < 0.01). Since 2005, nine episodes of ketoacidosis have been registered in eight patients corresponding to an incidence of 1.4 episodes per 100 patient years. Patient satisfaction was high one year after initiation of CSII $(p<0.01)$. Conclusion: Change of treatment to CSII is accompanied by an improvement in glycaemic control, very pronounced reduction in severe hypoglycaemia, low

*Corresponding author.

How to cite this paper: Gjessing, H.J., et al. (2014) Better Glycaemic Outcome, Low Levels of Acute Severe Complications, and High Patient Satisfaction in Routine Practice in Type 1 Diabetes Treated with an Insulin Pump. Journal of Diabetes Mellitus, 4, 304-310. http://dx.doi.org/10.4236/jdm.2014.44042 
levels of diabetic ketoacidosis, and pronounced patient satisfaction.

Keywords

Type 1 Diabetes, CSII, Glycaemic Control, Hypoglycaemia, Ketoacidosis, Patient Satisfaction

\section{Introduction}

Previously, treatment with continuous subcutaneous insulin infusion (CSII) was considered to be associated with an increased risk of acute complications such as severe hypoglycaemia and diabetic ketoacidosis (DKA) [1]. Therefore, the treatment with CSII was considered to be dangerous in Denmark in the late eighties and in the nineties, in spite of the fact that many groups in Denmark participated in early studies on CSII [2] [3]. In a review on this topic, only very few patients were treated with CSII in Denmark in 2003 [2]. In the same review, it was more likely, that CSII was associated with better metabolic control and lower risk of severe hypoglycaemia. Since then, treatment with CSII has increased pronouncedly in Denmark [3]. We initiated treatment with CSII in 2005 in the diabetes clinic in Fredericia, and data on the patients have been registered in a database. Early data from the database have been reported previously [4] [5]. Here, we report results from the database with data before and yearly until $\geq 5$ years of pump treatment during the period 2005-2013 with focus on glycaemic control, severe hypoglycaemia, DKA, and patient satisfaction.

\section{Patients and Methods}

The database was established in 2009-2010. Early data from 2005 to 2009 were obtained retrospectively from patient records and patient interviews. Data from 2009 were obtained prospectively. Patients were seen at least twice a year in the outpatient clinic. Once a year, data to the database were collected and registered in the database by the diabetes nurse. Data from patients having started CSII in other diabetes clinics were registered only from the first visit in Fredericia. If treatment with CSII vas stopped, this was registered in the database. The reason was stated, and the patient was no longer registered as an active patient. If patients moved away from the area, this was also registered in the database. Serious hypoglycaemia was defined as a low level of plasma-glucose combined with a need for help from another person.

Patient satisfaction was only measured in patients initiating CSII in Fredericia and only in patients entering the database from 2009. In all cases, patient satisfaction was measured prospectively. Patient satisfaction was measured by the validated Diabetes Treatment Satisfaction Questionnaire status (DTSQs) and change (DTSQc) version [6] [7]. Both questionnaires contain eight items scored on seven-point scales.

Six items (item 1, and items 4 - 8) measure treatment satisfaction (satisfaction with current treatment, convenience of current treatment, flexibility of current treatment, satisfaction with own understanding of their diabetes, how likely respondents are to recommend their present treatment, and how satisfied they are to continue the present treatment). The individual items scores are summed to produce a total treatment satisfaction score. Questions 2 and 3, concerning perceived frequency of hyperglycaemia and perceived frequency of hypoglycaemia, respectively, are treated separately from the satisfaction items and from each other. On these two items, low scores represent a good blood glucose control.

DTSQs scores range from $6=$ very satisfied to $0=$ very dissatisfied. DTSQc scores range from $+3=$ much more satisfied now to $-3=$ much less satisfied, with 0 (midpoint) representing no change. The total satisfaction scores when using the DTSQs ranges from 0 to 36 and when using the DTSQc from -18 to 18.

Both questionnaires were used since the DTSQs gives an evaluation of the level of satisfaction, while the DTSQc gives better information of patient preference, especially if the level of satisfaction with treatment is high before shifting to CSII. The DTSQs was filled in before initiation of CSII and after one year, and the DTSQc was filled in after one year.

Data are expressed as medians and ranges. Comparison of paired data is performed with the Student t-test for paired data or Wilcoxon's test for non-parametric paired data.

The database was established to monitor clinical quality of CSII treatment and was therefore approved by local authorities, but not by the local ethical committee. 


\section{Results}

By the end of the year 2013, the database contained 160 patients out of whom 143 were still followed at the outpatient clinic. In 1 patient the pump had been removed due to DKA and in 3 patients due to bad compliance, six patients had stopped CSII on their own initiative, and 7 patients had moved from the area. Among the 143 active patients, 39 have had their pump treatment initiated elsewhere and 70 were women. In these 39 patients, data before treatment with CSII were missing.

In this way, the database contained data before CSII on 104 patients, after one year on 97 patients, after 2 years on 82 patients, after 3 years on 66 patients, after 4 years on 68 patients, and after $\geq 5$ years on 60 patients. Data on at least one year on CSII treatment was available in 134 patients, since 9 of the patients in the database had initiated treatment with CSII during the year 2013.

The median age of the active patients was 43 years and median duration of pump therapy 4.4 years (Table 1 ).

There was a significant decrease in HbA1C from 64 (40 - 126) mmol/mol (8.0 (5.8 - 13.7)\%) (n = 104) before CSII to $60(36-98) \mathrm{mmol} / \mathrm{mol}(7.6 \%(5.4-11.1) \%)(\mathrm{n}=134)(\mathrm{p}<0.001)$ at the latest registration in 2013. The weight of the patients was unchanged.

The decrease in HbA1C was registered after one year and was maintained $\geq 5$ years of pump treatment (Table 2).

Figure 1 shows the distribution of patients before and the latest year on CSII treatment in different HbA1Cclasses. Generally, a shift towards more patients in lower HbA1C classes was observed on treatment with CSII. However, the same fraction of patients of approximately 15\% was seen with high HbA1C values above 75 $\mathrm{mmol} / \mathrm{mol}(9 \%)$ before and after CSII. The patients on CSII with HbA1C above $75 \mathrm{mmol} / \mathrm{mol}$ (9\%) were very young with a median age of 21 years.

Before CSII 60 episodes of severe hypoglycaemia were registered in 21 patients with a range of 1 - 10 episodes in each patient (Table 3). Each year after start of CSII the number of episodes of serious hypoglycaemia was pronouncedly reduced ( $<<0.01$ ). During the latest year of CSII among 134 patients only 5 episodes were registered in 5 patients.

Nine episodes of DKA were registered in 8 patients during the 9 years of CSII treatment. In one of the patients, treatment with CSII was stopped after the event of DKA.

Table 1. Clinical variables at last registration in 2013 of active patients in database (median and range) $(n=143)$.

\begin{tabular}{ccc}
\hline & Median & Range \\
\hline Duration of diabetes (yr) & $\mathbf{1 7}$ & $3-55$ \\
Duration of pump treatment (yr) & $\mathbf{4 . 4}$ & $0.5-28$ \\
Age (yr) & $\mathbf{4 0}$ & $18-73$ \\
Weight $(\mathrm{kg})$ & $\mathbf{7 9 . 5}$ & $46.4-153.7$ \\
BMI $\left(\mathrm{kg} / \mathrm{m}^{2}\right)$ & $\mathbf{2 5 . 5}$ & $20.0-40.8$ \\
\hline
\end{tabular}

Table 2. Yearly HbA1C (mmol/mol, \%) before and after pump therapy (median and range).

\begin{tabular}{|c|c|c|c|c|c|c|}
\hline \multirow{3}{*}{\multicolumn{2}{|c|}{$\begin{array}{l}\text { Number of years on } \\
\text { pump therapy years (n) }\end{array}$}} & \multicolumn{4}{|c|}{ HbA1C } & \multirow{3}{*}{$\mathrm{p}$} \\
\hline & & \multicolumn{2}{|c|}{ Median } & \multicolumn{2}{|c|}{ Range } & \\
\hline & & $\mathrm{mmol} / \mathrm{mol}$ & (\%) & $\mathrm{mmol} / \mathrm{mol}$ & (\%) & \\
\hline 0 & $(\mathrm{n}=104)$ & 64 & (8.0) & $40-126$ & $(5.8-13.7)$ & \\
\hline 1 & $(\mathrm{n}=97)$ & 58 & (7.5) & $41-90$ & $(5.9-10.4)$ & $<0.001$ \\
\hline 2 & $(\mathrm{n}=82)$ & 60 & (7.6) & $42-78$ & $(6.0-9.3)$ & $<0.001$ \\
\hline 3 & $(n=66)$ & 60 & (7.6) & $40-81$ & $(5.8-9.6)$ & $<0.001$ \\
\hline 4 & $(n=68)$ & 62 & (7.8) & 36 - 98 & $(5.4-11.1)$ & $<0.01$ \\
\hline$\geq 5$ & $(n=53)$ & 60 & (7.6) & $41-91$ & $(5.9-10.5)$ & $<0.01$ \\
\hline
\end{tabular}




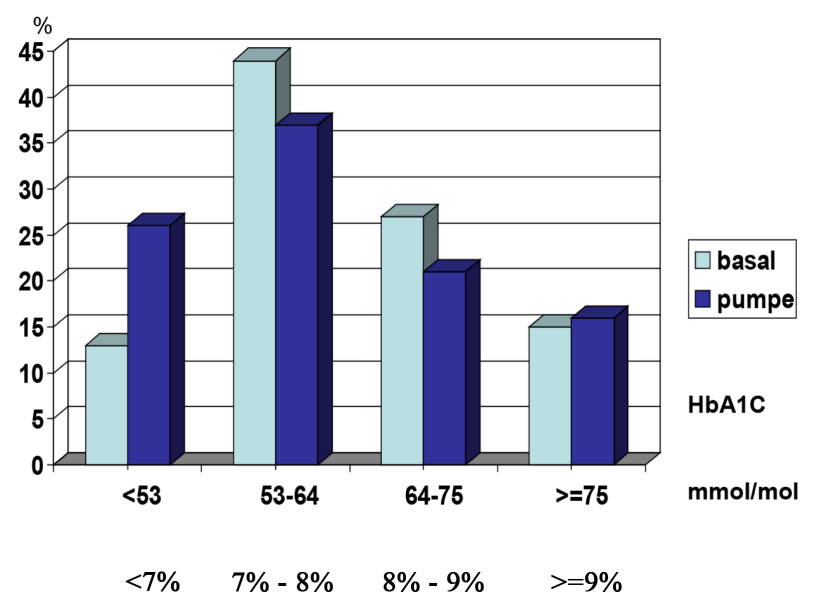

Figure 1. Percentage of patients with HbA1C at different intervals before $(n=104)$ and latest year $(134)$ of treatment with CSII.

\begin{tabular}{|c|c|c|c|c|c|}
\hline \multirow{2}{*}{\multicolumn{2}{|c|}{$\begin{array}{l}\text { Number of years } \\
\text { on pump therapy }\end{array}$}} & \multicolumn{3}{|c|}{ Severe hypoglycaemia } & \multirow{3}{*}{$\mathbf{p}^{*}$} \\
\hline & & \multirow{2}{*}{$\begin{array}{c}\text { Number of patients } \\
21\end{array}$} & \multirow{2}{*}{$\begin{array}{c}\text { Number of episodes } \\
60\end{array}$} & \multirow{2}{*}{$\begin{array}{c}\text { Range per subject } \\
1-10\end{array}$} & \\
\hline Baseline & $(n=104)$ & & & & \\
\hline 1 & $(\mathbf{n}=97)$ & 8 & 13 & $1-3$ & $<0.01$ \\
\hline 2 & $(\mathrm{n}=\mathbf{8 2})$ & 7 & 7 & - & $<0.01$ \\
\hline 3 & $(n=66)$ & 3 & 5 & $1-3$ & $<0.01$ \\
\hline 4 & $(\mathbf{n}=68)$ & 4 & 4 & - & $<0.02$ \\
\hline$\geq 5$ & $(n=53)$ & 1 & 1 & - & $<0.01$ \\
\hline Latest year & $(n=134)$ & 5 & 5 & - & $<0.01$ \\
\hline
\end{tabular}

${ }^{*}$ Comparison between number of episodes before and yearly after pump therapy.

Table 4 shows patient satisfaction measured by DTSQs before and after one year on CSII treatment. All aspects of patient satisfaction was improved by CSII except own understanding of diabetes. The satisfaction score was as high as 34 on treatment with CSII.

Table 5 shows patient satisfaction measured by DTSQc after one year. Here all aspects of patient satisfaction was improved by CSII including own understanding of diabetes. Again, the satisfaction score in favour of CSII was very high.

\section{Discussion}

It is more than 10 years ago that a Danish study reported very low use of CSII among Danish adult type 1 diabetic subjects [2]. Since then, a considerable rise in the use of CSII has been seen in Denmark [3]. We initiated treatment with CSII in 2005 and by the end of 2013 after nine years we followed 143 adult type 1 diabetic subjects treated with CSII in the diabetes clinic, Fredericia Hospital. In the national diabetes database in Denmark, 903 adult subjects with Type 1 diabetes are registered in the uptake area of the insulin pump clinic of Fredericia Hospital [8]. Thus, $15.8 \%$ of adult subjects with Type 1 diabetes are treated with CSII in our area. A similar prevalence of pump therapy is reported in other European countries [9]. In England the prevalence of pump therapy is only 6\% and in the USA 40\% [9] [10]. In Sweden, the national diabetes register reports that $21 \%$ of adult Type 1 diabetic subjects are treated with CSII in 2013 [11].

The results from our database represent the first Danish results on treatment with CSII after resumption of pump treatment in this millennium. Our study has shown that patients in routine practice treated with CSII im- 
Table 4. Patient satisfaction by use of Diabetes Treatment Satisfaction Questionnaire status (DTSQs) version before and after one year of treatment with continuous subcutaneous insulin infusion $(n=64)$.

\begin{tabular}{lcccccc}
\multicolumn{1}{c}{ Item } & \multicolumn{5}{c}{ Score, median (range) } \\
\cline { 2 - 6 } & At baseline & After one year & p Value \\
\hline 1. Satisfaction with current treatment & 4 & $(0-6)$ & 6 & $(3-6)$ & $<0.001$ \\
2. Perceived hyperglycemia & 4 & $(1-6)$ & 2 & $(0-5)$ & $<0.001$ \\
3. Perceived hypoglycemia & 3 & $(0-5)$ & 2 & $(0-5)$ & $<0.01$ \\
4. Convenience of current treatment & 3 & $(0-6)$ & 5 & $(1-6)$ & $<0.001$ \\
5. Flexibility of current treatment & 3 & $(0-6)$ & 6 & $(3-6)$ & $<0.001$ \\
6. Satisfaction with own understanding of diabetes & 5 & $(0-6)$ & 5 & $(4-6)$ & NS \\
7. Recommend present treatment & 3 & $(0-6)$ & 6 & $(5-6)$ & $<0.001$ \\
8. Satisfied to continue present treatment & 3 & $(0-6)$ & 6 & $(4-6)$ & $<0.01$ \\
Overall satisfaction score & 20 & $(1-33)$ & 34 & $(25-36)$ & $<0.001$ \\
\hline
\end{tabular}

NS $=$ non-significant; Scores range from $6=$ very satisfied, to $0=$ very dissatisfied. The overall satisfaction score is calculated by adding scores from item $1,4,5,6,7$ and 8.

Table 5. Patient satisfaction by use of Diabetes Treatment Satisfaction Questionnaire change (DTSQc) version one year after initiation of continuous subcutaneous insulin infusion $(n=64)$.

\begin{tabular}{lccc}
\multicolumn{1}{c}{ Item } & \multicolumn{2}{c}{ Score after one year } \\
\cline { 2 - 4 } & Median (range) & p Value \\
\hline 1. More/less satisfied with current treatment & 3 & $(0-3)$ & $<0.001$ \\
2. More/less perceived hyperglycemia & -2 & $(-3-2)$ & $<0.001$ \\
3. More/less perceived hypoglycemia & -2 & $(-3-1)$ & $<0.001$ \\
4. More/less convenience of current treatment & 3 & $(0-3)$ & $<0.001$ \\
5. Flexibility of current treatment & 3 & $(0-3)$ & $<0.001$ \\
6. More/less satisfied with own understanding of diabetes & 2 & $(0-3)$ & $<0.001$ \\
7. Recommend present treatment in comparison to previous & 3 & $(0-3)$ & $<0.001$ \\
8. Satisfied to continue present treatment in comparison to previous & 3 & $(0-3)$ & $<0.001$ \\
Overall satisfaction score in comparison to previous & 16 & $(0-18)$ & $<0.001$ \\
\hline
\end{tabular}

Scores range from $3=$ much more satisfied now, to -3 much less satisfied now, with $0=$ no change. Overall satisfaction difference is calculated by adding scores from items $1,4,5,6,7$ and 8 .

prove their glycaemic control and that the glycaemic control stay improved for $\geq 5$ years. The median HbA1C value of $60 \mathrm{mmol} / \mathrm{mol}(7.6 \%)$ with an improvement of $4 \mathrm{mmol} / \mathrm{mol}(0.4 \%)$ on pump therapy is in good accordance with meta-analysis on other studies on patients using rapid acting insulin analogues with CSII [12]-[14].

In our material, $15 \%$ of patients treated with CSII had HbA1C-levels above $75 \mathrm{mmol} / \mathrm{mol}$ (9\%). This group of patients had a low median age of 21 years. It is well-known that many young subjects are not well-controlled on treatment with CSII [12] and the use of sensors has been questioned in patients with age below 25 years [15]. Increased focus on young subjects treated with CSII is indicated. In 2012-2013, we have developed an adolescent care transition clinic with the paediatric diabetes clinic in order to obtain joint guidelines for indications and follow-up of patients treated with CSII. In patients with low compliance to CSII this treatment should be stopped. Until the end of 2013 we have stopped CSII due to DKA in one patient and due to low compliance in 3 patients. 
Patients are believed to be able to accurately recall episodes of severe hypoglycaemia within the last year corresponding to the recall period of the current study [16]. We registered very few episodes of serious hypoglycaemia in patients treated with CSII. During the latest year only 5 episodes were registered in 5 patients. This corresponds to only 3.7 episodes per 100 patient years. In an unselected material from Denmark the rate of severe hypoglycaemia was as high as 1.3 episodes per patient per year [17]. A similar low incidence of severe hypoglycaemia as in our study of 5 episodes per 100 patient years has also been registered in another study on patients treated with CSII [18]. Lower levels of severe hypoglycaemia on CSII compared to multiple injections have also been reported in recent meta-analyses [12]-[14]. One explanation to the very low rate of severe hypoglycaemia in our study could be that 52 patients used a glucose-sensor out of which 46 had low suspend function. Use of insulin pumps with glucose sensor and low suspend function protects against development of severe hypoglycaemia [19] [20]. More rigorous rules for obtaining a drivers license has been implemented in 2011 [21]. If a patient yearly develops more than one attack of severe hypoglycaemia the patient will loose the license. These rules could bring patients to withhold information about severe hypoglycaemia. The data in our database were retrospective in the period 2005-9, and this could limit our results, especially information about episodes of severe hypoglycaemia.

Nine episodes of DKA have been registered. This corresponds to an incidence of 1.4 episodes in 100 patient years. In a recent study on patients with Type 1 diabetes, 4 episodes of DKA are registered in Denmark pr 100 patient years [22]. Our data suggest that there is no increased risk of DKA in patients treated with CSII.

We found a very high degree of patient satisfaction with CSII treatment. Better patient satisfaction has also been recorded in a meta-analysis comparing patient satisfaction in patients with Type 1 diabetes, although the studies have not been of high quality [12] [23]. In our study, not all patients preferred CSII, since 6 patients shifted back from CSII to multiple injections by their own initiative.

In a paediatric setting, $11.3 \%$ of patients discontinued insulin pump therapy after a duration of pump therapy of up to 5 years [24]. In our clinic, 4 patients stopped pump therapy due to low compliance and 6 patients by own initiative, resulting in a discontinuation prevalence of $8.3 \%$ during a median follow-up of 4.4 years.

In conclusion, treatment with CSII is associated with better glycaemic control, very low levels of severe hypoglycaemia, few episodes of DKA, pronounced patient satisfaction, but also bad diabetes control especially in some young patients.

\section{Funding}

The study was supported by a grant from The Research Council of Hospital Lillebælt.

\section{Conflicts of Interest}

Hans J. Gjessing has received research support from Medtronic, Inc.

\section{References}

[1] Egger, M., Smith, G.D., Stettler, C. and Diem, P. (1997) Risk of Adverse Effects of Intensified Treatment in InsulinDependent Diabetes Mellitus: A Meta-Analysis. Diabetic Medicine, 14, 919-928. http://dx.doi.org/10.1002/(SICI)1096-9136(199711)14:11<919::AID-DIA456>3.0.CO;2-A

[2] Nørgaard, K. (2003) A Nationwide Study of Continuous Subcutaneous Insulin Infusion (CSII) in Denmark. Diabetic Medicine, 20, 307-311. http://dx.doi.org/10.1046/j.1464-5491.2003.00909.x

[3] Nørgaard, K. and Olsen, B. (2011) Changing Denmark from a Non-User Country to a Place Using Insulin Pumps-A Story on the Initiatives Taken. Infusystems International, 10, 25-29.

[4] Marmolin, E.A., Brødsgaard, J., Gjessing, H.J., Schousboe, K., Grodum, E., Jørgensen, U.L., et al. (2012) Better Treatment of Outpatients with Type 1 Diabetes after Introduction of Continuous Subcutaneous Insulin Infusion. Danish Midical Journal, 59, A4445.

[5] Gjessing, H.J., Jørgensen, U.L., Møller, C.C., Pedersen, J., Grodum, E. and Schousboe, K. (2013) Clinical Experiences with Continuous Insulin Infusion-Improved Glycaemic Control, Less Hypoglycaemia and Better and Pronounced Patient Satisfaction. Infusystems USA, 10, 1-5.

[6] Bradley, C. (1994) The Diabetes Treatment Satisfaction Questionnaire: DTSQ. In: Bradley, C., Ed., Handbook of Psychology and Diabetes: A Guide to Psychological Measurement in Diabetes Research and Practice, Harwood Academic Publishers, Chur, 111-132. 
[7] Bradley, C. (1999) The Diabetes Treatment Satisfaction Questionnaire (DTSQ): Change Version for Use Alongside Status Version Provides Appropriate Solution Where Ceiling Effects Occur. Diabetes Care, 22, 530-532. http://dx.doi.org/10.2337/diacare.22.3.530

[8] https://www.sundhed.dk/content/cms/87/4687_kom_\%C3\%A5rsrapport_diabetes_2013_14_28082014_final_offentlig g\%C3\%B8relse.pdf

[9] Pickup, J. (2011) Insulin Pumps. International Journal of Clinical Practice, 65, 16-19. http://dx.doi.org/10.1111/j.1742-1241.2010.02574.x

[10] White, H.D., Goenka, N., Furlong, N.J., Saunders, S., Morrison, G., Langridge, P., et al. (2014) The UK Service Level Audit of Insulin Pump Therapy in Adults. Diabetic Medicine, 31, 412-418. http://dx.doi.org/10.1111/dme.12325

[11] Swedish National Diabetes Register (2013) Annual Report 2013. https://www.ndr.nu/pdf/Annual_Report_NDR_2013.pdf

[12] Yeh, H.-C., Brown, T.T., Maruthur, N., Ranasinghe, P., Berger, Z., Suh, Y.D., et al. (2012) Comparative Effictiveness and Safety of Methods of Insulin Delivery and Glucose Monitoring for Diabetes Mellitus: A Systematic Review and Meta-Analysis. Annals of Internal Medicine, 157, 336-347. http://dx.doi.org/10.7326/0003-4819-157-5-201209040-00508

[13] Fatourechi, M.M., Kudva, Y.C., Murad, M.H., Elamin, M.B., Tabini, C.C. and Montori, V.M. (2009) Hypoglycemia with Intensive Insulin Therapy: A Systemic Review and Meta-Analysis of Randomised Trials of Continuous Subcutaneous Insulin Infusion versus Multiple Daily Injections. The Journal of Clinical Endocrinology and Metabolism, 94, 729-740. http://dx.doi.org/10.1210/jc.2008-1415

[14] Pickup, J.C. and Sutton, A.J. (2008) Severe Hypoglycaemia and Glycaemic Control in Type 1 Diabetes: Meta-Analysis of Multiple Daily Insulin Injections Compared with Continuous Subcutaneous Insulin Infusion. Diabetic Medicine, 25, 765-774. http://dx.doi.org/10.1111/j.1464-5491.2008.02486.x

[15] The Juvenile Diabetes Research Foundation Continuous Glucose Monitoring Study Group (2008) Continuous Glucose Monitoring and Intensive Treatment of Type 1 Diabetes. The New England Journal of Medicine, 359, 1464-1476. http://dx.doi.org/10.1056/NEJMoa0805017

[16] Pedersen-Bjergaard, U., Pramming, S. and Thorsteinsson, B. (2003) Recall of Severe Hypoglycaemia and Self-Estimated State of Awareness in Type 1 Diabetes. Diabetes/Metabolism Research and Reviews, 19, 232-240. http://dx.doi.org/10.1002/dmrr.377

[17] Pedersen-Bjergaard, U., Pramming, S., Heller, S.R., Wallace, T.M., Rasmussen, A.K., Jørgensen, H.V., et al. (2004) Severe Hypoglycaemia in 1076 Adult Patients with Type 1 Diabetes: Influence of Risk Markers and Selection. Diabetes/Metabolism Research and Reviews, 20, 479-486. http://dx.doi.org/10.1002/dmrr.482

[18] Shalitin, S., Gil, M., Nimri, R., de Vries, L., Gavan, M.Y. and Philip, M. (2010) Predictors of Glycaemic Control in Patients with Type 1 Diabetes Commencing Continuous Subcutaneous Insulin Infusion Therapy. Diabetic Medicine, 27, 339-347. http://dx.doi.org/10.1111/j.1464-5491.2009.02925.x

[19] Bergenstal, R.M., Klonoff, D.C., Garg, S.K., Bode, B.W., Meredith, M., Slover, R.H., et al. (2013) Threshold-Based Insulin Pump Interruption for Reduction of Hypoglycemia (Aspire In-Home Study). The New England Journal of Medicine, 369, 224-232. http://dx.doi.org/10.1056/NEJMoa1303576

[20] Ly, T.T., Nicholas, J.A., Retterath, A., Lim, E.M., Davis, E.A. and Jones, T.W. (2013) Effect of Sensor-Augmented Insulin Pump Therapy and Automated Insulin Suspension vs Standard Insulin Pump Therapy on Hypoglycaemia in Patients with Type 1 Diabetes. A Randomized Clinical Trial. Journal of the American Medical Association, 310, 12401247. http://dx.doi.org/10.1001/jama.2013.277818

[21] https://www.retsinformation.dk/Forms/R0710.aspx?id=139546

[22] Henriksen, O.M., Røder, M.E., Prahl, J.B. and Svendsen, O.L. (2007) Diabetic Ketoacidosis in Denmark. Incidence and Mortality Estimated from Public Health Registries. Diabetes Research and Clinical Practice, 76, 51-56. http://dx.doi.org/10.1016/j.diabres.2006.07.024

[23] Barnard, K.D., Lloyd, C.E. and Skinner, T.C. (2007) Systemic Literature Review: Quality of Life Associated with Insulin Pump Use in Type 1 Diabetes. Diabetic Medicine, 24, 607-617. http://dx.doi.org/10.1111/j.1464-5491.2007.02120.X

[24] de Vries, L., Grushka, Y., Lebenthal, Y., Shalitin, S. and Philip, M. (2010) Factors Associated with Increased Risk of Insulinpump Discontinuation in Pediatric Patients with Type 1 Diabetes. Pediatric Diabetes, 12, 506-512. http://dx.doi.org/10.1111/j.1399-5448.2010.00701.x 
Scientific Research Publishing (SCIRP) is one of the largest Open Access journal publishers. It is currently publishing more than 200 open access, online, peer-reviewed journals covering a wide range of academic disciplines. SCIRP serves the worldwide academic communities and contributes to the progress and application of science with its publication.

Other selected journals from SCIRP are listed as below. Submit your manuscript to us via either submit@scirp.org or Online Submission Portal.
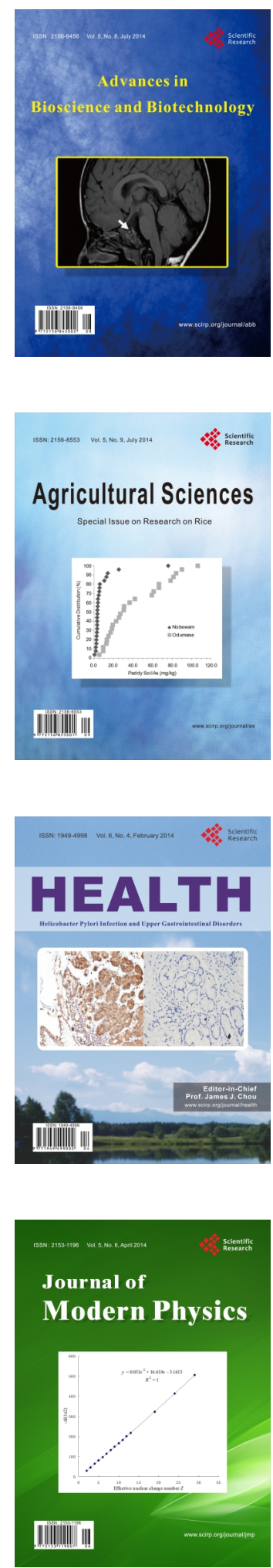
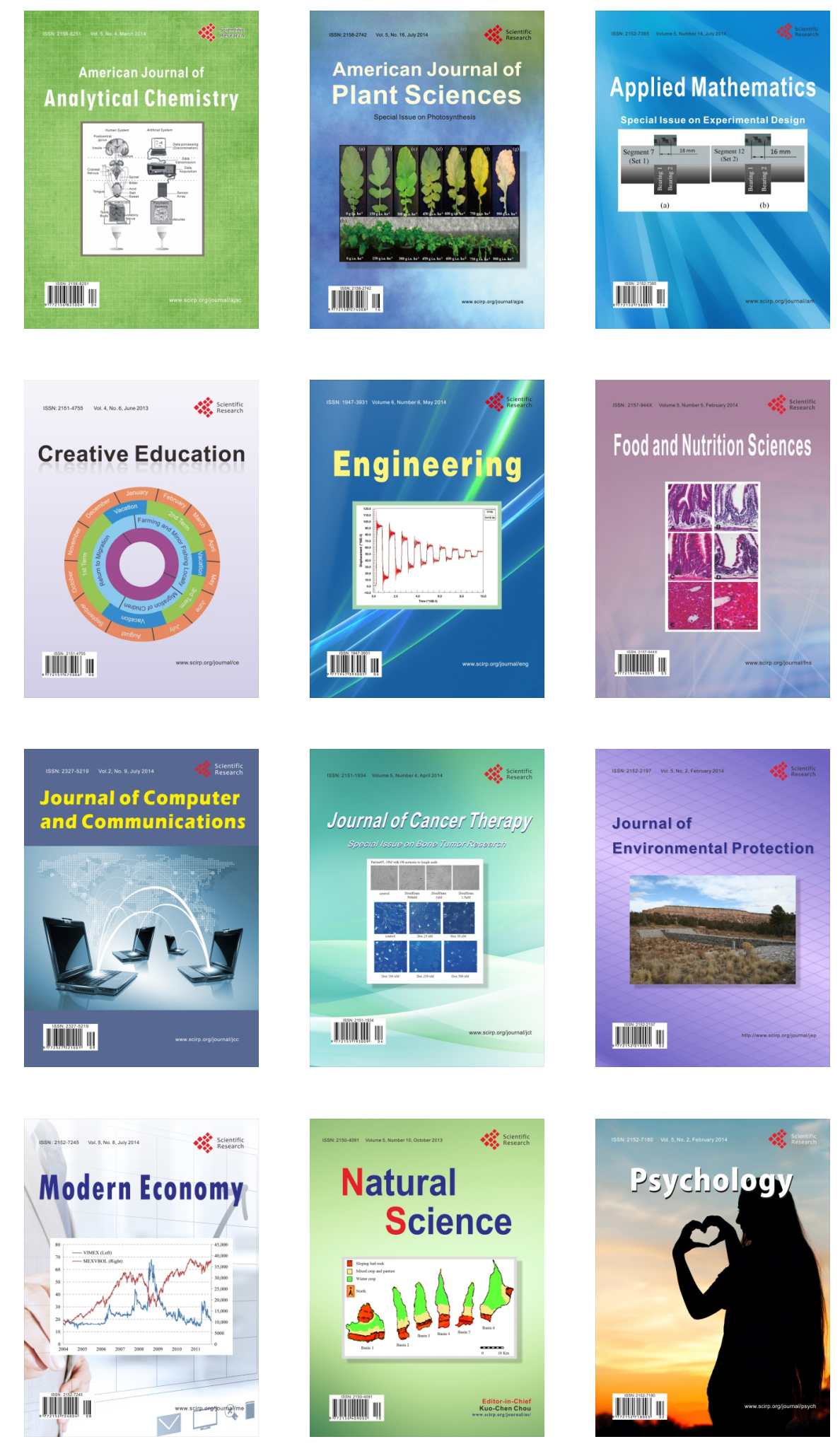